\title{
Multiple Charging of Poly(Propylene Glycol) by Binary Mixtures of Cations in Electrospray
}

\author{
Sándor Kéki, Lajos Nagy, György Deák, and Miklós Zsuga \\ Department of Applied Chemistry, University of Debrecen, Debrecen, Hungary
}

\begin{abstract}
Single, double and triple charging of poly(propylene glycol) $(\mathrm{PPG})\left(\mathrm{M}_{\mathrm{n}}=1900 \mathrm{~g} / \mathrm{mol}\right)$ in the presence of binary mixtures of cations $\left(\mathrm{Li}^{+}, \mathrm{Na}^{+}, \mathrm{K}^{+}, \mathrm{Cs}^{+}\right.$, and $\left.\mathrm{NH}_{4}^{+}\right)$under electrospray ionization (ESI) conditions were investigated. For these studies, sodium ion was selected as the reference cation, and the resulting ion-intensities were evaluated as a function of the $\left[\mathrm{Na}^{+}\right] /\left[\mathrm{C}^{+}\right]$ratio (where $\mathrm{C}^{+}$is the other cation, i.e., $\mathrm{Li}^{+}, \mathrm{K}^{+}, \mathrm{Cs}^{+}$and $\mathrm{NH}_{4}^{+}$). A linear relationship was found between $I_{\mathrm{Na}+} / I_{\mathrm{C}+}$ and $\left[\mathrm{Na}^{+}\right] /\left[\mathrm{C}^{+}\right]\left(I_{\mathrm{Na}+}\right.$ and $I_{\mathrm{C}+}$ stand for the intensity of the singly charged PPG molecules cationized with $\mathrm{Na}^{+}$and $\mathrm{C}^{+}$ions, respectively). The slope of the $I_{\mathrm{Na}+} / I_{\mathrm{C}+}-\left[\mathrm{Na}^{+}\right] /\left[\mathrm{C}^{+}\right]$plot $(\alpha)$ indicates the binding selectivity of $\mathrm{Na}^{+}$ions to PPG chains with respect to cation $\mathrm{C}^{+}$. In the case of the doubly charged PPG chains, the $I_{\mathrm{NaNa} 2+} / I_{\mathrm{NaC2}+}$ and $I_{\mathrm{NaC2}+} / I_{\mathrm{CC} 2+}$ versus $\left[\mathrm{Na}^{+}\right] /\left[\mathrm{C}^{+}\right]$ratio also yield straight lines with slopes of approximately $\alpha / 2$ and $2 \alpha$, respectively $\left(I_{\mathrm{NaNa} 2+}, I_{\mathrm{NaC2} 2}\right.$ and $I_{\mathrm{CC} 2+}$ are the intensity of the doubly charged PPG chains cationized with two $\mathrm{Na}^{+}$ions, $\mathrm{Na}^{+}$and $\mathrm{C}^{+}$ions, and two $\mathrm{C}^{+}$ions, respectively). Similarly, linear dependences with the $\left[\mathrm{Na}^{+}\right] /\left[\mathrm{C}^{+}\right]$ratio for the corresponding intensity ratios of the triply charged PPG were found. Based on the value of $\alpha$, the selectivity of the cations was found to increase in the order of $\mathrm{Li}^{+}<\mathrm{Cs}^{+} \approx \mathrm{Na}^{+}<\mathrm{K}^{+} \approx \mathrm{NH}_{4}^{+}$. The observed relative ion intensities are interpreted on the basis of the solution state equilibrium between PPG and the cations. In addition, the investigations showed that the abundances of the doubly and triply charged PPG-containing mixed cations can be optimized in a simple way using the value of $\alpha$. (J Am Soc Mass Spectrom 2005, 16, 152-157) (C 2004 American Society for Mass Spectrometry
\end{abstract}

$\mathrm{T}$ The application of ESI MS for the characterization of various synthetic polymers has been continuously increasing. Poly(ethylene glycol) (PEG), poly(propylene glycol) (PPG), and their copolymers are widely used in different important areas ranging from manufacturing of prepolymers for urethane-type resins [1] to medical and pharmaceutical applications such as drug carriers and stabilizers [2]. Charging of PEG with different metal ions and proton under ESI has been extensively studied [3-8] since Fenn's pioneering work [9]. The number of reports on PEG cationization with multiple ions, however, is very limited $[8,10,11]$. On the other hand, PPGs and their functionalized derivatives have received far less attention [11-13].

The conformation of PEG and PPG in solution may be completely different, therefore, the investigation of the cationization of these polymers with different alkali metal ions may shed more light on the understanding of the complexation behavior between alkali metal ions and molecules containing several carbon-carbon-oxygen units.

Recently, we reported the cationization of PEG under MALDI conditions [14] in the presence of various cations, and a good correlation was obtained between

Published online December 9, 2004

Address reprint requests to Dr. M. Zsuga, Department of Applied Chemistry, University of Debrecen, Egyetem ter 1. H-4010 Debrecen, Hungary. E-mail: zsugam@tigris.klte.hu the resulting ion intensities and the concentration ratio of the cations. As a continuation of our work, in this article, charging and multiple charging of PPG in the presence of binary mixtures of $\mathrm{NaCl}$ and other salts $\left(\mathrm{LiCl}, \mathrm{KCl}, \mathrm{CsCl}, \mathrm{NH}_{4} \mathrm{Cl}\right)$ under ESI conditions are reported. The results show that the ratio of the corresponding ion intensities is linearly dependent on the bulk molar ratio of $\mathrm{Na}^{+}$ions and the other cations.

\section{Experimental}

\section{Materials}

Poly(propylene glycol) (PPG) $\left(\mathrm{M}_{\mathrm{n}}=1900 \mathrm{~g} / \mathrm{mol}\right)$ was received from BorsodChem (Kazincbarcika, Hungary). $\mathrm{LiCl}, \mathrm{NaCl}, \mathrm{KCl}, \mathrm{CsCl}, \mathrm{NH}_{4} \mathrm{Cl}$, and methanol were purchased from Aldrich (Germany).

\section{Electrospray Ionization Time-of-Flight Mass Spectrometry (ESI-TOF MS)}

ESI-TOF MS measurements were performed on a BioTOF II instrument (Bruker Daltonics, Billerica, MA). Sample solutions were prepared in mixtures of methanol and water $(50 / 50 \mathrm{vol} / \mathrm{vol})$. The concentration of PPG was $0.1 \mathrm{mmol} / \mathrm{L}$. The concentration of $\mathrm{NaCl}$ and that of the other salts was kept constant at a total salt concentration of $1 \mathrm{mmol} / \mathrm{L}$. The solutions were intro- 


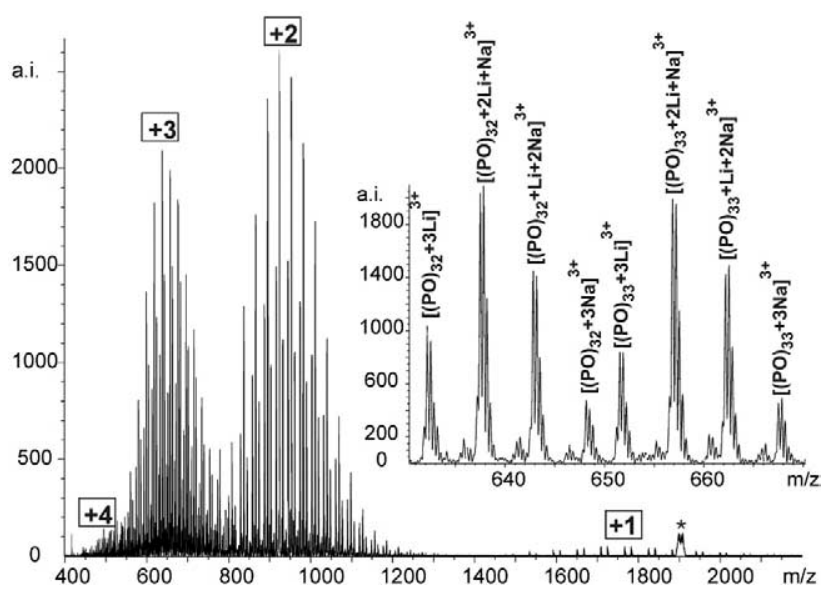

Figure 1. ESI-MS spectrum of PPG in the presence of binary mixtures of $\mathrm{Na}^{+}$and $\mathrm{Li}^{+}$ions. The numbers $+1,+2,+3$, and +4 stand for the singly, doubly, triply and quadruply charged PPG. The inset shows the partial MS spectrum for the triply charged PPG cationized with different number of $\mathrm{Na}^{+}$and $\mathrm{Li}^{+}$ions. ([PPG] $=0.1 \mathrm{mM},\left[\mathrm{Na}^{+}\right]=0.2 \mathrm{mM},\left[\mathrm{Li}^{+}\right]=0.8 \mathrm{mM}$, asterisks are ghost peaks originating from the TOF analyzer).

duced directly into the ESI source by a syringe pump (Cole-Parmer Instrument Company, Vernon Hills, IL.) at a flow rate of $2 \mu \mathrm{L} / \mathrm{min}$. The temperature of drying gas $\left(\mathrm{N}_{2}\right)$ was maintained at $100^{\circ} \mathrm{C}$. The voltages applied on the capillary entrance, capillary exit, and the first and the second skimmers were $-4500,120,40$, and $30 \mathrm{~V}$, respectively. The spectra were accumulated and recorded by a digitizer at a sampling rate of $2 \mathrm{GHz}$.

\section{Results and Discussion}

We examined the effect of four alkali metal ions $\mathrm{Li}^{+}$, $\mathrm{Na}^{+}, \mathrm{K}^{+}, \mathrm{Cs}^{+}$, and that of $\mathrm{NH}_{4}{ }^{+}$on the ESI-MS spectra of PPG with a moderately long chain $\left(\mathrm{M}_{\mathrm{n}}=1900\right.$ $\mathrm{g} / \mathrm{mol})$. The goal of this study was to determine the selectivity of these ions towards PPG and to obtain information on the factors, in this case multiple charging, which determine the relative intensities of PPG cationized with different numbers and types of ions. To address these aims, binary mixtures of salts in various concentration ratios were used for cationization of PPG and sodium ion was selected as the reference ion. The ESI-MS spectrum of PPG cationized with the binary mixtures of $\mathrm{Na}^{+}$and $\mathrm{Li}^{+}$ions is shown in Figure 1.

As seen in Figure 1, the singly, doubly, and triply charged PPG can easily be discerned. In addition, from a careful inspection of the low mass region of the spectrum $(\mathrm{m} / \mathrm{z} 450-600)$ the presence of quadruply charged PPG with low intensity can also be recognized. Doubly charged PPG cationized with two $\mathrm{Na}^{+}$, one $\mathrm{Na}^{+}$and one $\mathrm{Li}^{+}$and two $\mathrm{Li}^{+}$ions, i.e., adduct ions $\left[(\mathrm{PO})_{\mathrm{n}}+2 \mathrm{Na}\right]^{2+},\left[(\mathrm{PO})_{\mathrm{n}}+\mathrm{Na}+\mathrm{Li}\right]^{2+}$ and $\left[(\mathrm{PO})_{\mathrm{n}}+\right.$ $2 \mathrm{Li}^{2+}$ (where $\mathrm{PO}$ and $\mathrm{n}$ represent the propylene oxide repeating unit and the degree of polymerization, respectively) were formed. Similarly, triply charged adduct ions of PPG with the composition of $\left[(\mathrm{PO})_{\mathrm{n}}+\right.$
$3 \mathrm{Na}]^{3+},\left[(\mathrm{PO})_{\mathrm{n}}+2 \mathrm{Na}+\mathrm{Li}^{3+},\left[(\mathrm{PO})_{\mathrm{n}}+\mathrm{Na}+2 \mathrm{Li}\right]^{3+}\right.$ and $\left[(\mathrm{PO})_{\mathrm{n}}+3 \mathrm{Na}\right]^{3+}$ were generated as indicated in Figure 1 inset. It should be emphasized that the number of types of the adduct ions formed from binary mixtures of cations for a given charge level $(r)$ is expected statistically to be equal with $r+1$, i.e., 3 and 4 different types of adduct ions are formed from double and triple charging. As expected, formation of adduct ions obeying this simple statistics was observed in each case. The ion intensities within a series of the singly, doubly, and triply charged PPG varied significantly with the cation $\left(\mathrm{C}^{+}\right)$and the concentration ratio of the $\mathrm{Na}^{+}$and $\mathrm{C}^{+}$ ions.

\section{The Dependence of the Intensity Ratios} on the $\left[\mathrm{Na}^{+}\right] /\left[\mathrm{C}^{+}\right]$Ratio

Figure 2 shows the dependence of the intensity ratio of sodiated and potassiated PPG on the concentration ratio of the $\mathrm{Na}^{+}$and $\mathrm{K}^{+}$ions. The intensities referred throughout the text were obtained by summation of the corresponding intensities for each PPG oligomer peak appearing in the ESI-MS spectra.

As depicted in Figure 2, the values of $\mathrm{I}_{\mathrm{Na}+} / \mathrm{I}_{\mathrm{K}+}$ change linearly with those of $\left[\mathrm{Na}^{+}\right] /\left[\mathrm{K}^{+}\right]$and the slope of the line is denoted $\alpha$. The effect of the concentration ratio on the ion intensities of the doubly and triply charged PPG cationized with different numbers of $\mathrm{Na}^{+}$ and $\mathrm{K}^{+}$ions is shown in Figures 3 and 4 .

As seen in Figures 3 and 4, linear relationships with good linear correlation coefficients $\left(r^{2}>0.95\right)$ were found with relatively small values of intercepts and

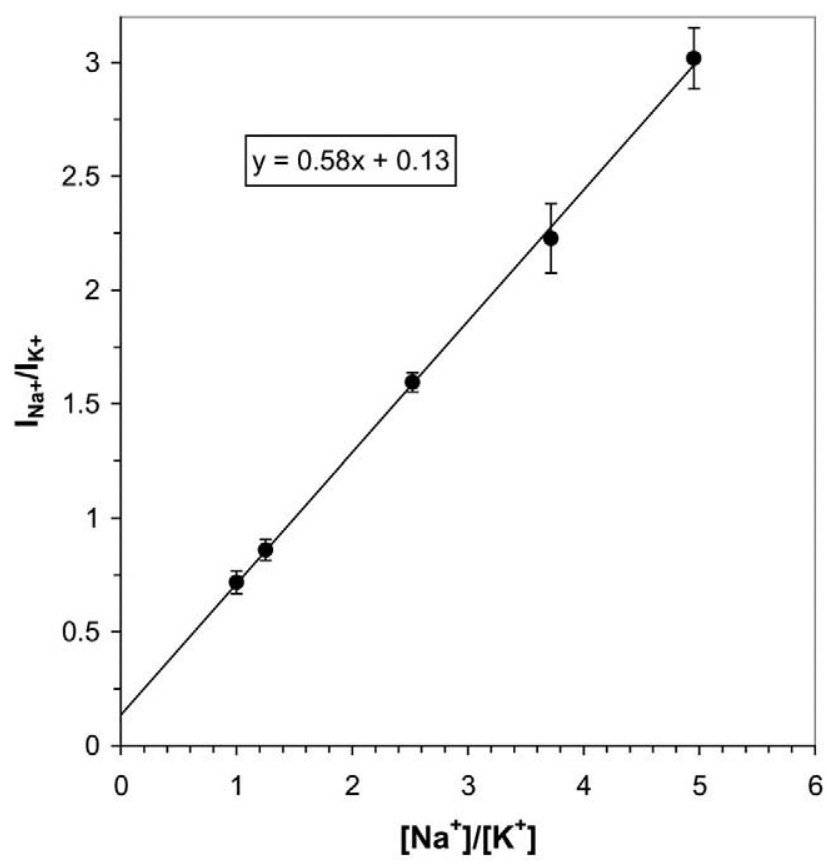

Figure 2. Intensity ratio of sodiated $\left(\mathrm{I}_{\mathrm{Na}}\right)$ and potassiated $\left(\mathrm{I}_{\mathrm{K}}\right)$ peaks versus $\left[\mathrm{Na}^{+}\right] /\left[\mathrm{C}^{+}\right]$plot for the singly charged PPG. ([PPG] $\left.=0.1 \mathrm{mM},\left[\mathrm{Na}^{+}\right]+\left[\mathrm{K}^{+}\right]=1 \mathrm{mM}\right)$. 


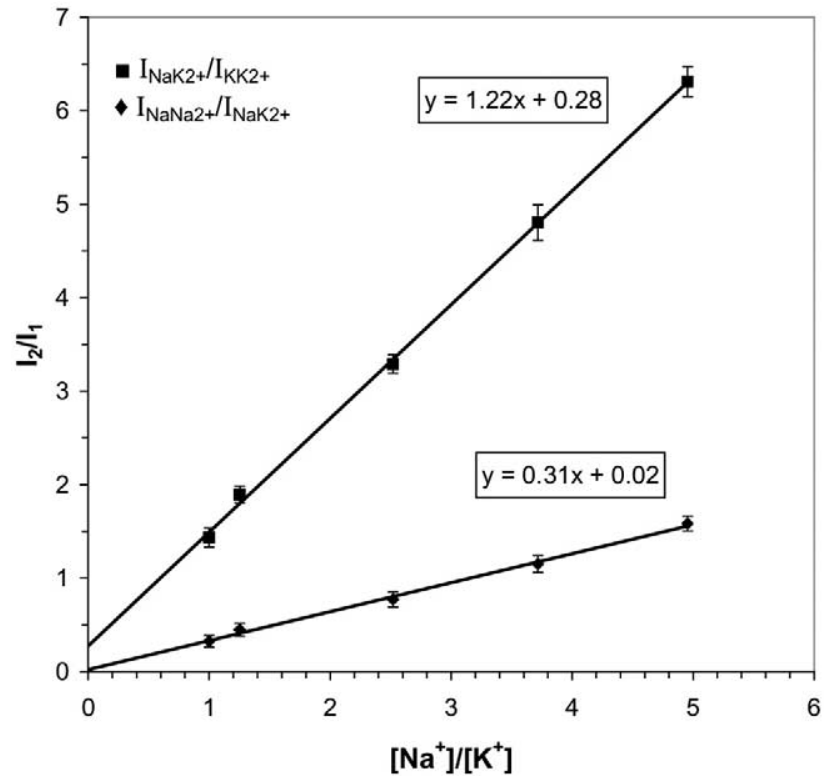

Figure 3. Intensity ratio of sodiated and potassiated PPG peaks versus $\left[\mathrm{Na}^{+}\right] /\left[\mathrm{C}^{+}\right]$plots for the doubly charged PPG. $([\mathrm{PPG}]=0.1$ $\left.\mathrm{mM},\left[\mathrm{Na}^{+}\right]+\left[\mathrm{K}^{+}\right]=1 \mathrm{mM}\right)$.

very different slopes. Linear relationships were also obtained between the corresponding intensity ratios and $\left[\mathrm{Na}^{+}\right] /\left[\mathrm{C}^{+}\right]$in the case of the other cations, i.e., $\mathrm{Li}^{+}$, $\mathrm{Cs}^{+}$, and $\mathrm{NH}_{4}{ }^{+}$. The values of the intercepts and the slopes for all the cations investigated are summarized in Table 1.

As it turns out from the data of Table 1, in the case of a given $\mathrm{Na}^{+}-\mathrm{C}^{+}$cation pair there is a good correlation between the slopes determined from the differently charged PPGs. Using the values of slopes in Table 1, one can easily observe that the slopes of $\mathrm{I}_{\mathrm{NaNa} 2+} / \mathrm{I}_{\mathrm{NaC2} 2}$ and $\mathrm{I}_{\mathrm{NaC2} 2} / \mathrm{I}_{\mathrm{CC} 2+}$ versus $\left[\mathrm{Na}^{+}\right] /\left[\mathrm{C}^{+}\right]$plots are approximately $\alpha / 2$ and $2 \alpha$, respectively. Similarly, for the triply charged PPGs, the $\mathrm{I}_{\mathrm{NaNaNa} 3+} / \mathrm{I}_{\mathrm{NaNaC3}+}, \mathrm{I}_{\mathrm{NaNaC} 3+} / \mathrm{I}_{\mathrm{NaCC} 3+}$, and $\mathrm{I}_{\mathrm{NaCC} 3+} / \mathrm{I}_{\mathrm{CCC} 3+}$ versus $\left[\mathrm{Na}^{+}\right] /\left[\mathrm{C}^{+}\right]$plots yield slopes with the values of approximately $\alpha / 3, \alpha$ and $3 \alpha$, respectively. However, in the case of $\mathrm{Cs}^{+}$(Table 1) relatively large differences in the values of $\alpha$ were obtained (considering the $\alpha$ values determined from the $\mathrm{I}_{\mathrm{NaNaCs}} / \mathrm{I}_{\mathrm{NaCsCs}}$ and $\mathrm{I}_{\mathrm{NaCsCs}} / \mathrm{I}_{\mathrm{CsCsCs}}$ plots). To explain the dependence of the corresponding intensity ratio on the $\left[\mathrm{Na}^{+}\right] /\left[\mathrm{C}^{+}\right]$ratio, we consider the following solution state equilibria (eqs 1 and 2) existing between PPG and $\mathrm{A}^{+}$and $\mathrm{B}^{+}$cations.

$$
\begin{aligned}
& (\mathrm{PO})_{\mathrm{n}}+\mathrm{A}^{+} \rightleftharpoons(\mathrm{PO})_{\mathrm{n}} \mathrm{A}^{+}\left(\mathrm{K}_{\mathrm{A}}\right) \\
& (\mathrm{PO})_{\mathrm{n}}+\mathrm{B}^{+} \rightleftharpoons(\mathrm{PO})_{\mathrm{n}} \mathrm{B}^{+}\left(\mathrm{K}_{\mathrm{B}}\right)
\end{aligned}
$$

Using the equilibrium constants $\mathrm{K}_{\mathrm{A}}$ and $\mathrm{K}_{\mathrm{B}}$, the concentration ratio of $(\mathrm{PO})_{\mathrm{n}} \mathrm{A}^{+}$and $(\mathrm{PO})_{\mathrm{n}} \mathrm{B}^{+}$can be expressed by the following equation:

$$
\begin{aligned}
& {\left[(\mathrm{PO})_{\mathrm{n}} \mathrm{A}^{+}\right] /\left[(\mathrm{PO})_{\mathrm{n}} \mathrm{B}^{+}\right]=\alpha\left[\mathrm{A}^{+}\right] /\left[\mathrm{B}^{+}\right], \quad \text { where } \alpha } \\
= & \mathrm{K}_{\mathrm{A}} / \mathrm{K}_{\mathrm{B}}
\end{aligned}
$$

Assuming equal ion formation and detection efficiencies for the same charge level, the measured intensity ratio will reflect the concentration ratio of $(\mathrm{PO})_{n} \mathrm{~A}^{+}$and $(\mathrm{PO})_{\mathrm{n}} \mathrm{B}^{+}$.

For the doubly charged PPG equilibria (eq 4) and (eq 5) are considered.

$$
\begin{aligned}
& (\mathrm{PO})_{\mathrm{n}} \mathrm{A}^{+}+\mathrm{A}^{+} \rightleftharpoons(\mathrm{PO})_{\mathrm{n}} \mathrm{AA}^{2+}\left(\mathrm{K}_{\mathrm{AA}}\right) \\
& (\mathrm{PO})_{\mathrm{n}} \mathrm{B}^{+}+\mathrm{B}^{+} \rightleftharpoons(\mathrm{PO})_{\mathrm{n}} \mathrm{BB}^{2+}\left(\mathrm{K}_{\mathrm{BB}}\right)
\end{aligned}
$$

The concentration ratio of $(\mathrm{PO})_{n} \mathrm{AA}^{2+}$ and $(\mathrm{PO})_{n} \mathrm{BB}^{2+}$ is then given by eq 6 :

$$
\frac{\left[(\mathrm{PO})_{\mathrm{n}} \mathrm{AA}^{2+}\right]}{\left[(\mathrm{PO})_{\mathrm{n}} \mathrm{BB}^{2+}\right]}=\frac{\mathrm{K}_{\mathrm{AA}}}{\mathrm{K}_{\mathrm{BB}}} \frac{\left[(\mathrm{PO})_{\mathrm{n}} \mathrm{A}^{+}\right]}{\left[(\mathrm{PO})_{\mathrm{n}} \mathrm{B}^{+}\right]} \frac{\left[\mathrm{A}^{+}\right]}{\left[\mathrm{B}^{+}\right]}
$$

The ratios of the equilibrium constants of the successive complexes when all coordination sites are equivalent can be determined statistically [15] using eq 7 .

$$
\frac{\mathrm{K}_{\mathrm{m}}}{\mathrm{K}_{\mathrm{m}+1}}=\frac{(\mathrm{m}+1)(\mathrm{p}-\mathrm{m}+1)}{\mathrm{m}(\mathrm{p}-\mathrm{m})}
$$

where $\mathrm{p}, \mathrm{m}$, and $\mathrm{p}-\mathrm{m}$ are the number of total coordination sites, occupied and available sites, respectively.

In the case of PPG, each monomeric unit contains an oxygen atom to which cations can attach. Therefore, the total number of coordination sites available for cations is expressed as $p=n+1$, where $n$ is the number of the

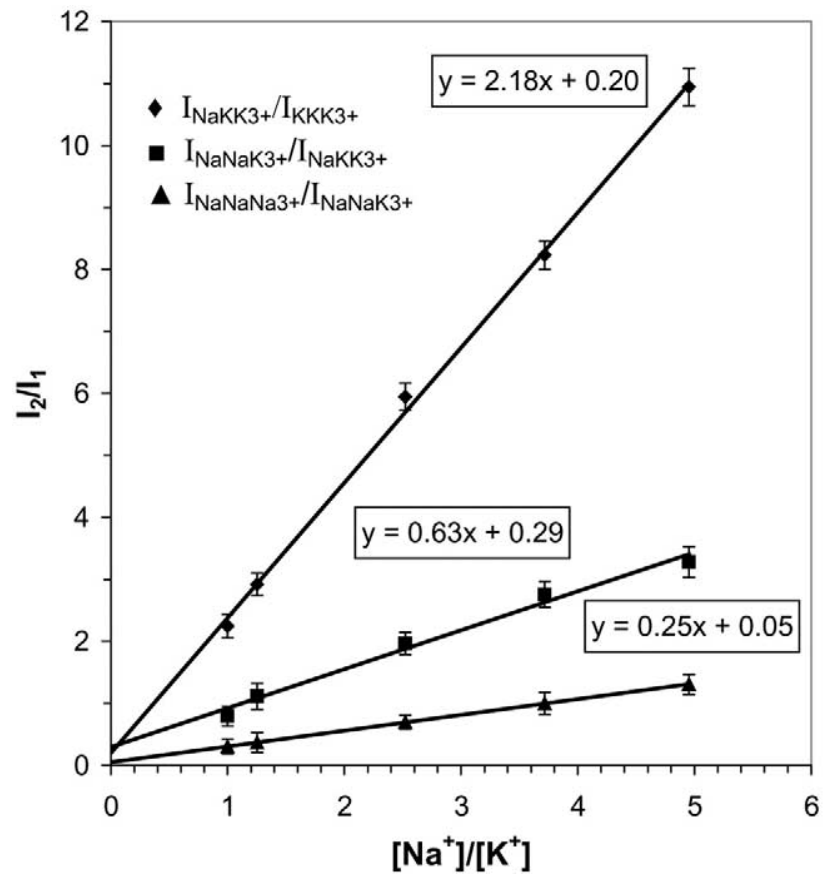

Figure 4. Intensity ratio of sodiated and potassiated PPG peaks versus $\left[\mathrm{Na}^{+}\right] /\left[\mathrm{C}^{+}\right]$plots for the triply charged PPG. ([PPG $=0.1$ $\left.\mathrm{mM},\left[\mathrm{Na}^{+}\right]+\left[\mathrm{K}^{+}\right]=1 \mathrm{mM}\right)$. 
Table 1. The slopes and the intercepts determined from the corresponding intensity ratios versus $\left[\mathrm{Na}^{+}\right] /\left[\mathrm{C}^{+}\right]\left(\mathrm{C}^{+}=\mathrm{Li}^{+}, \mathrm{K}^{+}, \mathrm{Cs}^{+}\right.$ and $\mathrm{NH}_{4}{ }^{+}$) plots. The first and the second number represent the slope and the intercept, respectively

\begin{tabular}{|c|c|c|c|c|c|}
\hline & & $\mathrm{Li}^{+}$ & $\mathrm{K}^{+}$ & $\mathrm{Cs}^{+}$ & $\mathrm{NH}_{4}{ }^{+}$ \\
\hline & & \multicolumn{4}{|c|}{ singly charged } \\
\hline 1. & $\mathrm{I}_{\mathrm{Na}} / \mathrm{I}_{\mathrm{C}}(\alpha)$ & \multicolumn{4}{|c|}{ doubly charged } \\
\hline $\begin{array}{l}2 . \\
3 .\end{array}$ & $\begin{array}{l}\mathrm{I}_{\mathrm{NaNa}} / \mathrm{I}_{\mathrm{NaC}}(\alpha / 2) \\
\mathrm{I}_{\mathrm{NaC}} / \mathrm{I}_{\mathrm{CC}}(2 \alpha)\end{array}$ & $\begin{array}{l}1.78 ; 0.02 \\
7.38 ; 0.09\end{array}$ & $\begin{array}{l}0.31 ; 0.02 \\
1.22 ; 0.28\end{array}$ & $\begin{array}{l}0.61 ; 0.11 \\
2.37 ; 0.24\end{array}$ & $\begin{array}{l}0.28 ; 0.01 \\
0.83 ; 0.15\end{array}$ \\
\hline & & \multicolumn{4}{|c|}{ triply charged } \\
\hline $\begin{array}{l}4 . \\
5 . \\
6 .\end{array}$ & $\begin{array}{l}\mathrm{I}_{\mathrm{NaNaNa}} / \mathrm{I}_{\mathrm{NaNaC}}(\alpha / 3) \\
\mathrm{I}_{\mathrm{NaNaC}} / \mathrm{I}_{\mathrm{NaCC}}(\alpha) \\
\mathrm{I}_{\mathrm{NaCC}} / \mathrm{I}_{\mathrm{CCC}}(3 \alpha)\end{array}$ & $\begin{array}{l}1.09 ; 0.08 \\
2.82 ; 0.07 \\
7.23 ; 0.41\end{array}$ & $\begin{array}{l}0.25 ; 0.05 \\
0.63 ; 0.29 \\
2.18 ; 0.20\end{array}$ & $\begin{array}{l}0.33 ; 0.15 \\
0.99 ; 0.25 \\
4.12 ; 0.21\end{array}$ & $\begin{array}{l}0.21 ; 0.11 \\
0.55 ; 0.21 \\
1.36 ; 0.35\end{array}$ \\
\hline
\end{tabular}

repeating units and the additional coordination site comes from the terminal $\mathrm{OH}$ group. Considering the degree of polymerization of PPG (DP $=24-45)$, in the limit case when the total number of the available coordination sites is high, eq 7 gives a value of approximately 2 for $\mathrm{K}_{1} / \mathrm{K}_{2}$, i.e., $\mathrm{K}_{\mathrm{AA}}=\mathrm{K}_{\mathrm{A}} / 2$ and $\mathrm{K}_{\mathrm{BB}}=\mathrm{K}_{\mathrm{B}} / 2$. It should be noted, however, that the backbone coordination sites in the doubly and triply charged PPG ions are not equivalent due to the differing Coulombic repulsion in the different PPG charge states.

Substituting $\mathrm{K}_{\mathrm{AA}}=\mathrm{K}_{\mathrm{A}} / 2$ and $\mathrm{K}_{\mathrm{BB}}=\mathrm{K}_{\mathrm{B}} / 2$ and $\alpha=$ $\mathrm{K}_{\mathrm{A}} / \mathrm{K}_{\mathrm{B}}$ into eq 6 , we get eq 8 .

$$
\left[(\mathrm{PO})_{\mathrm{n}} \mathrm{AA}^{2+}\right] /\left[(\mathrm{PO})_{\mathrm{n}} \mathrm{BB}^{2+}\right]=\alpha^{2}\left[\mathrm{~A}^{+}\right]^{2} /\left[\mathrm{B}^{+}\right]^{2}
$$

Furthermore, for the ratio $\left[(\mathrm{PO})_{n} \mathrm{AA}^{2+}\right] /\left[(\mathrm{PO})_{n} \mathrm{AB}^{2+}\right]$ and $\left[(\mathrm{PO})_{\mathrm{n}} \mathrm{AB}^{2+}\right] /\left[(\mathrm{PO})_{\mathrm{n}} \mathrm{BB}^{2+}\right]$ using the equilibrium constants and $\alpha$ eq 9 and eq 10 can be derived.

$$
\begin{aligned}
& {\left[(\mathrm{PO})_{\mathrm{n}} \mathrm{AA}^{2+}\right] /\left[(\mathrm{PO})_{\mathrm{n}} \mathrm{AB}^{2+}\right]=\alpha / 2\left[\mathrm{~A}^{+}\right] /\left[\mathrm{B}^{+}\right]} \\
& {\left[(\mathrm{PO})_{\mathrm{n}} \mathrm{AB}^{2+}\right] /\left[(\mathrm{PO})_{\mathrm{n}} \mathrm{BB}^{2+}\right]=2 \alpha\left[\mathrm{A}^{+}\right] /\left[\mathrm{B}^{+}\right]}
\end{aligned}
$$

Similarly, the corresponding concentration ratio for the triply charged PPG can be expressed by eqs 11-13.

$$
\begin{aligned}
& {\left[(\mathrm{PO})_{\mathrm{n}} \mathrm{AAA}^{3+}\right] /\left[(\mathrm{PO})_{\mathrm{n}} \mathrm{AAB}^{3+}\right]=\alpha / 3\left[\mathrm{~A}^{+}\right] /\left[\mathrm{B}^{+}\right]} \\
& {\left[(\mathrm{PO})_{\mathrm{n}} \mathrm{AAB}^{3+}\right] /\left[(\mathrm{PO})_{\mathrm{n}} \mathrm{ABB}^{3+}\right]=\alpha\left[\mathrm{A}^{+}\right] /\left[\mathrm{B}^{+}\right]} \\
& {\left[(\mathrm{PO})_{\mathrm{n}} \mathrm{ABB}^{3+}\right] /\left[(\mathrm{PO})_{\mathrm{n}} \mathrm{BBB}^{3+}\right]=3 \alpha\left[\mathrm{A}^{+}\right] /\left[\mathrm{B}^{+}\right]}
\end{aligned}
$$

Eqs 9-13, which are derived from the solution state equilibrium of PPG with cations $\mathrm{A}^{+}$and $\mathrm{B}^{+}$describe well the experimentally determined slopes from different plots (Table 1). Furthermore, the advantage of eqs $9-13$ is that they allow to estimate of the value of $\alpha$ from the intensity distributions of the doubly and triply charged polymer adduct ions in cases when the determination of $\alpha$ from the singly charged distribution is difficult, e.g., due to low signal intensity. For instance, the value of $\alpha$ for the $\mathrm{Na}^{+}-\mathrm{Cs}^{+}$system can be deter- mined using the results for the doubly and/or triply charged distributions. In this case, due to the low signal intensity of the singly charged species, the value of $\alpha$ cannot be directly obtained from this distribution. Using the values of $\alpha$ in Table 1, it can be established that the selectivity of the cations towards the PPG chains increases in the order of $\mathrm{Li}^{+}<\mathrm{Cs}^{+} \approx \mathrm{Na}^{+}<\mathrm{K}^{+} \approx$ $\mathrm{NH}_{4}{ }^{+}$. This trend correlates with the increasing size of the cation, except for the $\mathrm{Cs}^{+}$ion. The dependence of the selectivities of cations to PPG on the chain length was evaluated by plotting the intensity ratios of PPG cationized with sodium and the other cations as a function of the chain length (low intensity peaks, i.e., at the two edges of the distribution, because of the low signal to noise ratio were not considered). Using this method, we did not observe any significant chain length dependence.

\section{The Dependence of the Relative Intensities on the $\left[\mathrm{Na}^{+}\right] /\left[\mathrm{C}^{+}\right]$Ratio}

The relative ion intensities of the doubly charged PPG, i.e., the intensity of PPG cationized with two $\mathrm{A}^{+}\left(\beta_{\mathrm{AA}}\right)$, one $\mathrm{A}^{+}$and one $\mathrm{B}^{+}\left(\beta_{\mathrm{AB}}\right)$, and two $\mathrm{B}^{+}\left(\beta_{\mathrm{BB}}\right)$ ions with respect to the sum for all the doubly charged PPG can be derived using eqs $8-10$ to give eqs $14-16$.

$$
\begin{aligned}
& \beta_{\mathrm{AA}}=\alpha^{2} \mathrm{x}^{2} /\left(\alpha^{2} \mathrm{x}^{2}+2 \alpha \mathrm{x}+1\right)=\alpha^{2} \mathrm{x}^{2} /(\alpha \mathrm{x}+1)^{2} \\
& \beta_{\mathrm{AB}}=2 \alpha \mathrm{x} /(\alpha \mathrm{x}+1)^{2} \\
& \beta_{\mathrm{BB}}=2 \alpha \mathrm{x} /(\alpha \mathrm{x}+1)^{2}
\end{aligned}
$$

where $x=\left[\mathrm{A}^{+}\right] /\left[\mathrm{B}^{+}\right]$.

The experimentally determined $\beta_{\mathrm{AA}}, \beta_{\mathrm{AB}}$, and $\beta_{\mathrm{BB}}$ values versus $\left[\mathrm{A}^{+}\right] /\left[\mathrm{B}^{+}\right]$ratio for the doubly charged PPG together with the curves calculated by eqs $14-16$ are plotted in Figure 5.

As seen in Figure 5, eqs 14-16 render the experimentally observed dependences of the relative ion intensities on the $\left[\mathrm{A}^{+}\right] /\left[\mathrm{B}^{+}\right]$ratio. One can also calculate from eq 15 that the maximum value of the relative ion intensity for 
the doubly charged species containing mixed cations $\left(\beta_{\mathrm{AB}, \max }\right)$ is 0.5 occurring at $\left[\mathrm{A}^{+}\right] /\left[\mathrm{B}^{+}\right]=1 / \alpha$.

The intensity of PPG cationized with three $\mathrm{A}^{+}$ $\left(\beta_{\mathrm{AAA}}\right)$, two $\mathrm{A}^{+}$and one $\mathrm{B}^{+}\left(\beta_{\mathrm{AAB}}\right)$, one $\mathrm{A}^{+}$and two $\mathrm{B}^{+}$ $\left(\beta_{\mathrm{ABB}}\right)$, and three $\mathrm{B}^{+}\left(\beta_{\mathrm{BBB}}\right)$ ions relative to the sum for all the triply charged PPG can be calculated on the basis of eqs $11-13$ to obtain eqs $17-20$.

$$
\begin{aligned}
& \beta_{\mathrm{AAA}}=\alpha^{3} \mathrm{x}^{3} /\left(\alpha^{3} \mathrm{x}^{3}+3 \alpha^{2} \mathrm{x}^{2}+3 \alpha \mathrm{x}+1\right)=\alpha^{3} \mathrm{x}^{3} /(\alpha \mathrm{x}+1)^{3} \\
& \beta_{\mathrm{AAB}}=3 \alpha^{2} \mathrm{x}^{2} /(\alpha \mathrm{x}+1)^{3} \\
& \beta_{\mathrm{ABB}}=3 \alpha \mathrm{x} /(\alpha \mathrm{x}+1)^{3} \\
& \beta_{\mathrm{BBB}}=1 /(\alpha \mathrm{x}+1)^{3}
\end{aligned}
$$

The dependences of the $\beta_{\mathrm{AAA}}, \beta_{\mathrm{AAB}}, \beta_{\mathrm{ABB}}$, and $\beta_{\mathrm{BBB}}$ values on the $\left[\mathrm{A}^{+}\right] /\left[\mathrm{B}^{+}\right]$ratio for the triply charged PPG together with those calculated by eqs $17-20$ are depicted in Figure 6.

As it turns out from Figure 6, eqs 17-20 describe the dependences of the different $\beta$ values on the $\left[\mathrm{A}^{+}\right] /\left[\mathrm{B}^{+}\right]$ ratio well. It can also be rationalized from eqs $17-20$ that the maximum values of the relative ion intensities for the triply charged adduct ions composed of mixed cations is $12 / 27$ for both $\left[(\mathrm{PO})_{\mathrm{n}}+2 \mathrm{~A}+\mathrm{B}\right]^{3+}$ and $\left[(\mathrm{PO})_{\mathrm{n}}+\mathrm{A}+\right.$ $2 \mathrm{~B}]^{3+}$. The maxima occur at the concentration ratio $\mathrm{x}=$ $2 / \alpha$ (in the case of $\left.\left[(\mathrm{PO})_{\mathrm{n}}+2 \mathrm{~A}+\mathrm{B}\right]^{3+}\right)$ and $\mathrm{x}=1 /(2 \alpha)($ in

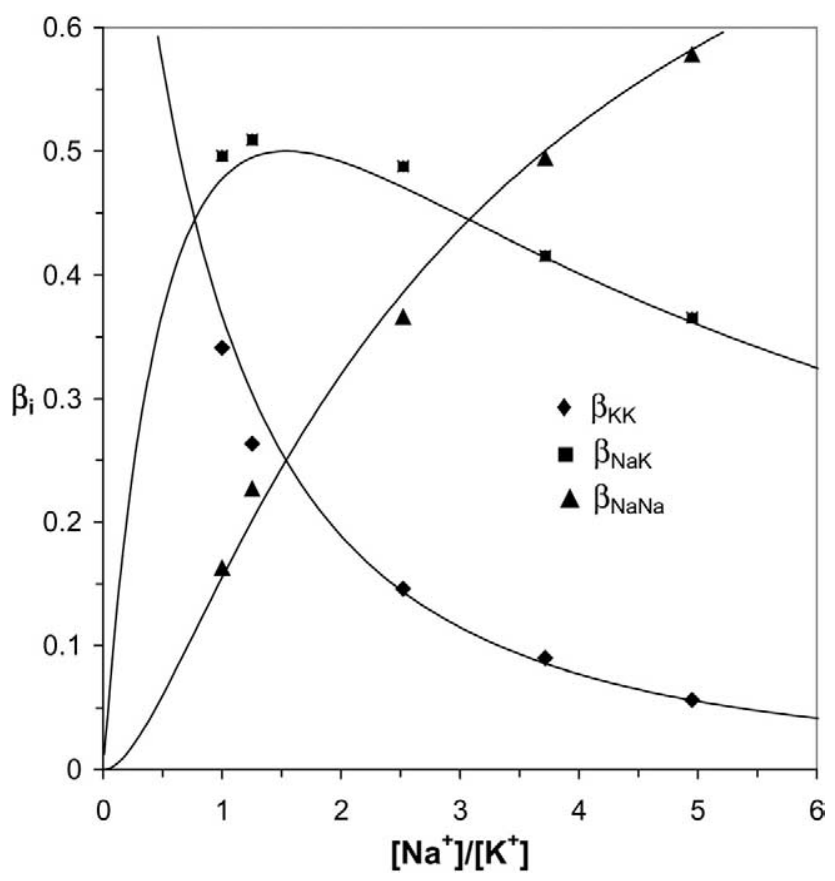

Figure 5. The relative ion intensities of PPG cationized with two sodium ions $\left(\beta_{\mathrm{NaNa}}\right)$, one sodium and one potassium $\left(\beta_{\mathrm{NaK}}\right)$, and two potassium ions $\left(\beta_{\mathrm{KK}}\right)$ versus $\left[\mathrm{Na}^{+}\right] /\left[\mathrm{K}^{+}\right]$plots. The solid lines represent the calculated values using eq 14-16 with $\alpha=0.65$. $\left(\left[\mathrm{PPG}=0.1 \mathrm{mM},\left[\mathrm{Na}^{+}\right]+\left[\mathrm{K}^{+}\right]=1 \mathrm{mM}\right)\right.$.

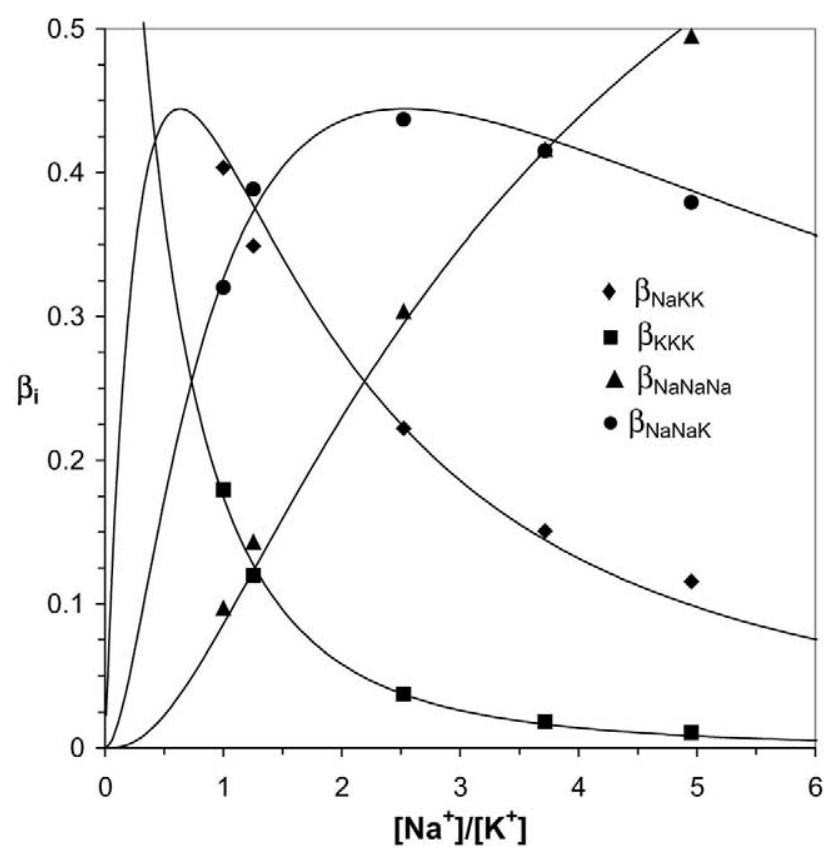

Figure 6. The relative ion intensities of PPG cationized with three sodium ions $\left(\beta_{\mathrm{NaNaNa}}\right)$, two sodium and one potassium $\left(\beta_{\mathrm{NaNaK}}\right)$, one sodium and two potassium $\left(\beta_{\mathrm{NaKK}}\right)$, and three potassium ions $\left(\beta_{\mathrm{KKK}}\right)$ versus $\left[\mathrm{Na}^{+}\right] /\left[\mathrm{K}^{+}\right]$plots. The solid lines represent the calculated values using eq 17-20 with $\alpha=0.75$. $\left(\left[\mathrm{PPG}=0.1 \mathrm{mM},\left[\mathrm{Na}^{+}\right]+\left[\mathrm{K}^{+}\right]=1 \mathrm{mM}\right)\right.$.

the case of $\left.\left[(\mathrm{PO})_{\mathrm{n}}+\mathrm{A}+2 \mathrm{~B}\right]^{3+}\right)$. Our results also show that the abundance of the adduct ions composed of mixed cations can easily be maximized using the value of $\alpha$ and the above considerations. For example, to obtain maximum abundance for the doubly charged $\left[(\mathrm{PO})_{\mathrm{n}}+\mathrm{A}+\right.$ $\mathrm{B}]^{2+}$ or the triply charged $\left[(\mathrm{PO})_{\mathrm{n}}+2 \mathrm{~A}+\mathrm{B}\right]^{3+}$ mixed adduct ions, $\left[\mathrm{A}^{+}\right] /\left[\mathrm{B}^{+}\right]$ratio at $\mathrm{x}=1 / \alpha$ or $\mathrm{x}=2 / \alpha$, respectively, should be applied. Such considerations are very useful when, e.g., one intends to perform MS/MS experiments on the mixed adduct ions.

Although our observation reflects a correlation of the ESI MS spectra to the equilibrium state in bulk solution, it is also possible that the observed binding selectivity of cations to PPG is related to the charged droplets or gas phase processes and not to the bulk solution properties as suggested by one of the reviewers. Interestingly, it was shown by vibrational spectroscopic studies performed on the bulk mixture of PPG of low molecular weight and alkali thiocyanates (LiSCN, NaSCN, and KSCN) that the strength of the interaction between the metal ion and the ether groups of PPG (as well as $\mathrm{OH}$ end groups) increased in the order $\mathrm{Li}^{+}>\mathrm{Na}^{+}>\mathrm{K}^{+}$ [16]. This trend is opposite to that observed in our ESI studies. However, the complex formation between metal ions and PPG is affected by many factors such as the solvent environment, the counter ions, the polymer dynamics, and local conformation of PPG, etc. [11, 16, 17]. Therefore, the discrepancy in the trends may be due to MS sampling, the different solvents, and counter ions used as well as different local conformation and polymer dynamics of PPG. 


\section{Acknowledgments}

This work was financially supported by the grants $\mathrm{T}$ 037448, $\mathrm{T}$ 042740, M 28369, and M 36872, MU-00204/2001 given by OTKA (National Scientific Research Fund, Hungary), grant NKF3A/0036/ 2002, and the Bolyai János and the Békésy György Fellowship.

\section{References}

1. Seneker, S. D.; Barksby, N. Lawrey, B. D. Polyol molecular weight distribution effects on mechanical and dynamic properties of polyurethanes; Proceedings of the Polyurethanes Expo 98; Dallas, TX, September 1998; pp 195-205.

2. Adams, M. L.; Lavasanifar, A.; Kwon, G. S. Amphiphilic block copolymers for drug delivery. J. Pharm. Sci. 2003, 92, 13431355.

3. Nohmi, T.; Fenn, J. B. Electrospray mass spectrometry of poly(ethylene glycols) with molecular weights up to five million. J. Am. Chem. Soc. 1992, 114, 3241-3246.

4. Fenn, J. B.; Rosell, J.; Meng, C. K. In electrospray ionization, how much pull does an ion need to escape its droplet prison? J. Am. Soc. Mass Spectrom. 1997, 8, 1147-1157.

5. Maziarz, E. P., III; Baker, G. A.; Mure, J. V.; Wood, T. D. A comparison of electrospray versus nanoelectrospray ionization Fourier transform mass spectrometry for the analysis of synthetic poly(dimethylsiloxane)/poly(ethylene glycol) oligomer blends. Int. J. Mass Spectrom. 2000, 202, 241-250.

6. Chen, R.; Li, L.; Edmonton, A.B. Lithium and transition metal ions enable low energy collision-induced dissociation of polyglycols in electrospray ionization mass spectrometry. J. Am. Soc. Mass Spectrom. 2001, 12, 832-839.

7. Varray, S.; Aubagnac, J. L.; Lamaty, F.; Lazaro, R.; Martinez, J.; Enjalbal, C. Poly(ethylene glycol) in electrospray ionization (ESI) mass spectrometry. Analusis 2000, 28, 263-268.
8. Bogan, M. J.; Agnes, G. R. Poly(ethylene glycol) doubly and singly cationized by different alkali metal ions: Relative cation affinities and cation-dependent resolution in a quadrupole ion trap mass spectrometer. J. Am. Soc. Mass Spectrom. 2002, 13, 177-186.

9. Wong, S. F.; Meng, C. K.; Fenn, J. B. Multiple charging in electrospray ionization of poly(ethylene glycols). J. Phys. Chem. 1988, 92, 546-550.

10. Chan, K. W. S.; Cook, K. D. Mass spectrometric study of interactions between poly(ethylene glycols) and alkali metal salts. Macromolecules 1983, 16, 1736-1740.

11. Mattern, D. E.; Hercules D. M. Laser mass spectrometry of polyglycols: Comparison with other mass spectral techniques. Anal. Chem. 1985, 57, 2041-2046.

12. Okuno, S.; Ohmoto, M.; Arakawa, R. Analysis of polypropyleneglycols using electrospray ionization mass spectrometry. Effects of cationizing agents on the mass spectra. Eur. J. Mass Spectrom. 2003, 9, 97-103.

13. Barton, Z.; Kemp, T. J.; Buzy, A.; Jennings, K. R. Mass spectral characterization of the thermal degradation of poly(propylene oxide) by electrospray and matrix-assisted laser desorption ionization. Polymer 1995, 36, 4927-4933.

14. Kéki, S.; Szilágyi, L. Sz.; Deák, Gy.; Zsuga, M. Effects of different alkali metal ions on the cationization of poly(ethylene glycol)s in matrix-assisted laser desorption/ionization mass spectrometry: a new selectivity parameter. J. Mass Spectrom. 2002, 37, 1074-1080.

15. Beck, M. T. Chemistry of Complex Equilibria;Akadémia Publisher: Budapest, Hungary, 1970; Chap III, p 43.

16. Manning, J.; Frech, R.; Hwang, E. Vibrational spectroscopic studies of cation effects in low molecular weight poly(propylene oxide) complexed with lithium, sodium, and potassium thiocyanate. Polymer 1990, 31, 2245-2252.

17. Ferry, A.; Jacobsson, P.; Stevens, J. R. Studies of ionic interactions in poly(propylene glycol) 4000 complexed with triflate salts. J. Phys. Chem. 1996, 100, 12574-12582. 